\title{
Mídia regional e local: aspectos conceituais e tendências
}

\author{
Local and regional media: \\ conceptual aspects and tendencies \\ Medios regionales y locales: \\ aspectos conceptuales y tendencias
}

\author{
CICILIA M. \\ KROHLING PERUZZO
}

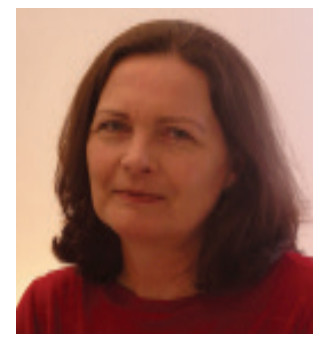

Mestre em Comunicação Social pela Umesp e doutora em Ciências da Comunicação pela Escola de Comunicações e Artes da Universidade de São Paulo. Docente do Programa de Pós-Graduação em Comunicação Social da Universidade Metodista de São Paulo. Ex-presidente (1999-2002) da Intercom - Sociedade Brasileira de Estudos Interdisciplinares da Comunicação. Foi professora da Universidade Federal do Espírito Santo e da Associação Educacional de Vitória (ES). É autora dos livros Relações públicas no modo de produção capitalista e Comunicação nos movimentos populares: a participação na construção da cidadania e organizadora de diversas coletâneas de Comunicação. Publicou grande número de artigos em revistas científicas no País e no Exterior. E.mail: kperuzzo@uol.com.br. 
PERUZZO, Cicilia M. Krohling. Mídia regional e local: aspectos conceituais e tendências. Comunicação \& Sociedade. São Bernardo do Campo: Póscom-Umesp, a. 26, n. 43, p. 67-84, 1o. sem. 2005.

\section{Resumo}

Trata-se de um texto sobre mídia regional e local que tem como objetivos situar alguns dos seus principais aspectos conceituais e traçar um breve panorama das tendências atuais do jornalismo praticado neste tipo de mídia. Baseia-se em pesquisa bibliográfica e em análise assistemática de jornais e programas de rádio e de televisão de diferentes cidades brasileiras. Evidencia-se que a informação de proximidade se constitui numa demanda regional, mas os jornais e as televisões, na prática, estão envolvidos em contradições, motivadas pelos vínculos políticos e interesses econômicos, que, além de comprometer a informação de qualidade e isenta, acabam por reproduzir estilos e menosprezar a força do local enquanto fonte de informação.

Palavras-chave: Mídia local - Jornalismo regional - Proximidade - Comunidade.

\section{Abstract}

This paper deals with local and regional media, focusing on locating some of their main conceptual aspects and structuring a brief overview of the current tendencies of the journalism practiced in this type of media. The study is based on bibliographical research and on a non-systematic research of newspapers, radio and television programs of different Brazilian cities. As a conclusion, it is clearly observed that the information of proximity is characterized by a regional demand, but the newspapers and tv are, in fact, involved in contradictions, motivated by political connections and economic interests, that in addition to compromising the impartiality of information end up reproducing styles and undermining local strength as source of information.

Keywords: Local media - Regional journalism - Proximity - Community.

\section{Resumen}

El presente texto es sobre medios regionales y locales y tiene como objetivos ubicar algunos de sus principales aspectos conceptuales y trazar un breve panorama de las tendencias actuales del periodismo practicado en este tipo de medios. Este texto es resultado de una investigación bibliográfica y de un análisis asistemático de periódicos y programas de radio y de televisión de diferentes ciudades brasileras. Se constata que la información próxima se constituye en una demanda regional, pero los periódicos y las televisiones, en la práctica, se ven involucrados en contradicciones motivadas por los vínculos políticos e intereses económicos, que, además de comprometer la calidad e imparcialidad de la información, acaban reproduciendo estilos y menospreciando la fuerza de lo local como fuente de información.

Palavras claves: Medio local - Periodismo regional - Proximidad - Comunidad. 
$\mathrm{E}$ ste texto objetiva situar os principais aspectos conceituais sobre mídia regional e local e traçar um breve panorama das tendências atuais do jornalismo praticado nestes tipos de meios de comunicação no Brasil. Mídia local denota uma comunicação baseada em informação de proximidade. Na prática, ela é perpassada por distorções motivadas pela forma com que as relações de produção das notícias e de outros conteúdos midiáticos se processam, mas de uma maneira geral cumpre uma importante função social.

A abordagem se ancora em pesquisa bibliográfica e em análise assistemática de jornais e programas de rádio e de televisão de diferentes cidades do Brasil. Não pretende dar conta de todo o fenômeno. Apenas aponta tendências majoritárias.

\section{Contextualização do tema}

Mídia local existe desde que surgiram os meios de comunicação de massa. Historicamente o jornal, o rádio e a televisão, ao nascer, atingem apenas um raio de abrangência local ou regional. Alguns destes meios de comunicação desenvolvem seu potencial de alcance nacional ou internacional, outros permanecem locais. O rádio, por exemplo, é eminentemente local, embora possa percorrer também longas distâncias. No Brasil, a televisão começa a alterar sua vocação local com o advento do videoteipe - em $1960^{1}$ - e de outras tecnologias das comunicações que permitiram a formação de redes e a conseqüente nacionalização das transmissões das produções televisivas rea-

$\overline{1 . S e g u n d o ~ S e r g i o ~ M a t t o s ~(2000, ~ p . ~ 266), ~ f o i ~ a ~ T V ~ T u p i ~ q u e ~ u s o u ~ o ~ v i d e o t e i p e ~}$ pela primeira vez, em 1960, na gravação de um teleteatro, uma adaptação de Hamlet, de William Shakespeare, enquanto a primeira telenovela diária só começou a ser exibida em 1963, graças à utilização do videoteipe (Reimão, 2000, p. 70). 
lizadas nos grandes centros urbanos pelas emissoras matrizes.

$\mathrm{O}$ videoteipe permitiu a circulação de fitas gravadas e a transmissão de programas em nível nacional. Mas, como lembra Sandra Reimão (2000, p. 70), ele permitiu a troca de produções entre filiais de uma emissora, embora não se pudesse ainda falar propriamente em redes nacionais, o que só se dará a partir de 1969, com a instalação da rede de microondas da Empresa Brasileira de Telecomunicações (Embratel).

Com o desenvolvimento da globalização da economia e das comunicações, num primeiro momento, chegou-se a pressupor o fim da comunicação local, para em seguida se constatar o contrário: a revalorização da mesma, sua emergência ou consolidação em diferentes contextos e sob múltiplas formas.

Na Europa há abundante bibliografia sobre mídia local já nos anos 1980 e 1990, enquanto no Brasil o fenômeno, na perspectiva em que é tratado atualmente, começa a despertar mais interesse de setores da academia desde o final da década de 1990. Porém, diga-se de passagem, que a produção acadêmica à qual nos referimos é precedida por uma outra modalidade de comunicação, a denominada comunicação alternativa, popular ou comunitária, mais precisamente a comunicação no contexto dos movimentos sociais. Este tipo de comunicação que, em grande parte, também se configura como sendo uma comunicação local, está muito presente em estudos acadêmicos nos anos 1980, em nosso país ${ }^{2}$.

Há razões históricas e culturais que ajudam a configurar a existência e o grau de importância da mídia regional e local em cada contexto. No caso da Europa, as comunidades autônomas (Galícia, Catalunha etc.), com suas especificidades lingüísticas e culturais, tendem a desenvolver mais os seus próprios meios de comunicação.

No Brasil, o desenvolvimento das comunicações, principalmente através de grandes redes de televisão, acabou priorizando a centralização da produção de mensagens nos grandes centros urbanos, de onde passam a ser disseminadas por todo o país. Essa estratégia evolui com a política de "integração nacio-

2. Ver: FESTA, R. e SILVA, C. E. Lins da (orgs.). Comunicação popular e alternativa no Brasil. São Paulo: Paulinas, 1986; e a revista Comunicação e Sociedade - São Bernardo do Campo: PósCom-IMS, n. 6, 1982.

3. A TV Gazeta, de Vitória (ES), por exemplo, além de duas e meia horas 70 - Comunicação e Sociedade 43 
nal" herdada da época da ditadura militar e se desenvolve com o avanço das telecomunicações e das mídias digitais.

No entanto, a produção local e regional nunca esteve ausente dos meios de comunicação, sejam eles televisões, rádios ou jornais. A televisão reserva espaço para a produção de programas locais, embora ele seja muito pequeno em relação ao número total de horas que ela fica no ar, além de ser destinado, majoritariamente, a noticiários. A Rede Globo, por exemplo, tem duas e meia horas diárias de noticiários locais, mais umas brechas de horários opcionais em altas horas da noite ou de madrugada, além de uns poucos horários aos sábados e domingos ${ }^{3}$. Os jornais de circulação nacional, como a Folha de S. Paulo e o Jornal do Brasil, apesar de terem suas editorias voltadas para questões de economia, política etc., nacionais e internacionais, destinam grande parte do seu espaço para assuntos de sua cidade-sede e para anúncios publicitários captados na região.

É, contudo, no final dos anos 1990 que parece haver uma redescoberta do local pela grande mídia, embora haja experiências anteriores em televisão regional, como a da Rede Brasil Sul (RBS), que em 1963 já instalou as primeiras emissoras no interior ${ }^{4}$ do Rio de Grande do Sul.

$\mathrm{O}$ interesse da grande mídia pelo local, num primeiro momento, apresenta-se mais por seu lado mercadológico do que pela produção de conteúdo regionalizado. A televisão, por exemplo, explora a diferenciação local como nicho de mercado, interessada que está em captar os recursos provenientes da publicidade do interior do país ${ }^{5}$.

Evidências da importância do regional/local são encontradas no incremento das redes regionais, no aumento de

diárias com programas jornalísticos, ocupa mais uma hora e cinco minutos com programas aos domingos (Jornal do Campo e Painel de Domingo) e trinta e cinco minutos aos sábados com o programa Em Movimento (Silva, 2004, p. 63).

4. A TV Gaúcha instalou suas primeiras retransmissoras interioranas em Vasconcelos (município de Tape), São Lourenço do Sul e Cascata para atingir Pelotas e Rio Grande (Cruz, 1996, p. 41).

5. Ver Peruzzo (2003). 
programas produzidos nas regiões e na maior preocupação em se cobrir jornalisticamente as cidades vizinhas e não apenas as cidades-sede da estação geradora. Redes regionais de televisão, como, por exemplo, as Empresas Pioneiras de Televisão (EPTV), abarcando a região de Campinas e Ribeirão Preto, no estado de São Paulo, e de Varginha, em Minas Gerais, e a TV Tem, com emissoras em Bauru, São José do Rio Preto, Sorocaba e Itapetininga, no estado de São Paulo, gradualmente vêm ampliando suas áreas de coberturas, chegando a atingir atualmente, juntas, cerca de 717 municípios.

Os programas produzidos localmente são, principalmente, os jornalísticos a partir da realidade e dos acontecimentos locais, mas há também outros gêneros de programas, como debates e documentários.

No entanto, há entraves que prejudicam a expressividade local através da mídia televisiva tradicional. Primeiro, o limite de tempo imposto pelas redes, como já mencionado. Segundo, os horários permitidos para inserção local, excetuando os programas jornalísticos, são os de menor audiência - tarde da noite ou de madrugada. Terceiro, a exigência de enquadramento nos padrões nacionais das grandes redes, que direcionam as temáticas e o modo de expressão, acabando por inibir o afloramento dos sotaques regionais e maior inserção de mão-de-obra local.

\section{Questão local: aspectos conceituais}

As questões teóricas relativas à comunicação comunitária sempre estiveram, de certo modo, bastante claras academicamente. Por um lado, se buscam os pontos de ligação nos conceitos clássicos de comunidade, consolidados, mas em processo de constante atualização há mais de meio século. Por outro lado, exatamente dentro desse processo de atualização, a mobilização social fez surgir um novo tipo de comunicação comunitária, inerente a organizações e movimentos populares, que propiciou inúmeros estudos no Brasil e em vários outros países da Américas Latina. Nesta perspectiva, a partir dos anos 1980, se cria um rico acervo de publicações dando conta de análises e formulações teóricas sobre comunicação comunitária - também chamada de popular, 
alternativa, participativa etc.

No entanto, como a sociedade é complexa, várias práticas de empresas comerciais regionais também se apresentam como comunitárias, quando nem toda comunicação local pode ser assim denominada. Trata-se de uma confusão natural, visto que o comunitário não pressupõe uma compreensão uníssona, nem a comunicação popular tem o propósito de trabalhar com exclusividade com os temas comunitários.

Aproximadamente na segunda metade dos anos 1990, no Brasil, a mídia regional e local começa a chamar a atenção pelo interesse demonstrado pelos segmentos de públicos locais e regionais. Ela passa a ampliar os espaços para programas produzidos nas regiões e a difundir conteúdos antes restritos aos meios de comunicação comunitários engajados em lutas sociais nas localidades.

Com a retomada da questão local e dos meios de comunicação locais nos anos recentes, várias indagações sobre esses fenômenos vêm despertando o interesse de estudiosos da comunicação. Por que há um revigoramento da mídia local no contexto da globalização? O que é local? O que é região? O que é comunicação comunitária? Quais as fronteiras entre o comunitário, o local e o regional? Toda mídia local é comunitária? As respostas não são simples, nem conclusivas, já que a mídia local ainda está se autoconstruindo.

Uma das respostas aponta para as relações global-local, local-regional-nacional, local-comunitário e local-global que envolvem os meios de comunicação. Isto levanta um primeiro aspecto no que diz respeito à mídia local e comunitária: a questão das fronteiras e, ao mesmo tempo, da quebra de fronteiras ${ }^{6}$. Se a mídia já tem por praxe transgredir fronteiras, de espaço ou de tempo, no âmbito regional estas se tornam ainda mais tênues. O princípio sociológico defendido por Alain Bourdin (2001), de que é impossível definir fronteiras precisas entre o regional, o local e o comunitário, é valido também para a circulação dos meios de comunicação.

6. Ver Peruzzo (2003). 
Um segundo aspecto é a questão do território. Hoje está superada a noção de território geográfico como determinante do local e do comunitário. Para lá das dimensões geográficas, surge um novo tipo de território ${ }^{7}$, que pode ser se base cultural, ideológica, idiomática, de circulação da informação etc. Dimensões como as de familiaridade no campo das identidades históricoculturais (língua, tradições, valores, religião etc.) e de proximidade de interesses (ideológicos, políticos, de segurança, crenças etc.) são tão importantes quanto as de base física. São elementos propiciadores de elos culturais e laços comunitários que a simples delimitação geográfica pode não ser capaz de conter.

Um terceiro aspecto implícito na discussão sobre as localidades é a globalização, mais precisamente a relação global-local. Já está bastante claro que o fato da globalização - da universalização ou da ocidentalização do mundo, como preferem alguns ${ }^{8}$ - impulsiona uma revalorização do local, ao invés de debelá-lo, como se prognosticou num primeiro momento. Houve, assim, a superação da tendência pessimista de considerar que as forças globalizadas - da economia, da política e da mídia - detêm o poder infalível de sufocar as sociedades e as culturas nos níveis nacional e local. A realidade vai evidenciando que o local e o global fazem parte de um mesmo processo: condicionam-se e interferem um no outro, simultaneamente.

Como diz Milton Santos (2002, p. 321-322), "a localidade se opõe à globalidade, mas também se confunde com ela. $\mathrm{O}$ mundo, todavia, é nosso estranho. Entretanto se, pela sua essência, ele pode esconder-se, não pode fazê-lo pela sua existência que se dá nos lugares". Mas, ao mesmo tempo, não se pode esquecer que o local tem suas especificidades. Ele evoca "aquilo que se pode ver, tocar, aprender e, portanto, ser compreendido. Sem dúvida, é desde os espaços locais que se definem os contornos da vida diária, onde se constrói a personalidade social e onde se faz a aprendizagem social" (López García9 ${ }^{9}$ 1999, p. 247).

A mídia local se ancora na informação gerada dentro do

7. Ver Ortiz (1999) e Hall (1998).

8. Id., ib.

74 - Comunicação e Sociedade 43 
território de pertença e de identidade em uma dada localidade ou região. Porém, ela não é monolítica. Não há uniformidade no tipo de vínculo dos meios de comunicação em suas regiões, pois a inserção (mais ou menos) comprometida localmente depende da política editorial de cada veículo.

Assim sendo, a inserção local pode ocorrer com o propósito de esmiuçá-lo ou simplesmente para valer-se de algumas coisas do local, mas sem desvincular-se de sua vocação "nacional". Neste caso, a inserção se caracteriza como hesitante ou "semi-local", conforme Gabriel Ringlet (apud Camponez, 2002, p.100-102). Ou seja, a empresa de comunicação se integra mais como estratégia de ampliação do mercado do que por vocação regional.

Conceitualmente, há ainda um debate em torno da relação território geográfico-informação local. Gabriel Ringlet (apud Camponez, 2002, p. 108), por exemplo, vê um papel estruturante da geografia na definição da informação local: "numa primeira análise, e diferentemente dos outros tipos de informação, a imprensa local define-se menos pelo seu conteúdo que pelo seu espaço geográfico". Já Carlos Camponez (2002, p. 128), acredita que

o território revela-se (...) insuficiente para, por si só, (...) explicar a imprensa regional e local. (...) A proximidade já não se mede em metros. Devemos estar preparados para conceber a produção de conteúdos que, embora longe de nossas casas, nos são próximos, bem como para assistir à produção nas regiões de conteúdos tão homogeneizados e massificados quanto os das grandes corporações de media.

O autor se apóia na idéia de Teun van Dick de que a proximidade não se limitaria àquela advinda do local, mas compreenderia também a da consonância ideológica e de identificações psico-afetivas. Para Camponez (2002, p. 113), próximo, em jornalismo, é também a representação que o meio faz de seu território e, conseqüentemente, dos destinatários das suas mensagens. Ele diz ainda que a questão da proximidade é transversal ao jornalismo no esforço de comunicar conteúdos pertinentes

9. Faz referência a Luís Alvarez Pousa. 
aos seus leitores.

Do nosso ponto de vista, o conceito de proximidade pode ser explorado a partir de diferentes perspectivas, mas, quando se trata de mídia local e regional, ele se refere aos laços originados pela familiaridade e pela singularidade de uma determinada região, que têm muito a ver com a questão do locus territorial.

Como afirma Jean-Marie Launay (apud Camponez, 2002, p. 110), “quem diz imprensa regional, diz informação local. É, de resto, nesta ligação conceitual entre a sua localização territorial e a territorialização dos seus conteúdos que a imprensa regional e local constrói a sua razão de ser, a sua especificidade e a sua força".

Contudo, salientamos que estamos nos referindo à mídia de propriedade privada comercial. No espaço local há também os meios de comunicação comunitária, que têm características próprias. As diferenças fundamentais deste tipo de comunicação se circunscrevem ao âmbito dos vínculos sociais, às estratégias de sustentabilidade, ao processo produtivo e aos conteúdos. $\mathrm{O}$ protagonismo principal está nos cidadãos, que, através de organizações da sociedade civil sem fins lucrativos, instituem processos de comunicação com vistas à mobilização social e à ampliação da cidadania. Funcionam na base de doações, apoio cultural, trabalho voluntário, profissionais liberados por instituições de origem (sindicatos, ONGs) para prestar serviços em associações coletivas e, às vezes, contrata-se um número pequeno de funcionários para manter o serviço oferecido em funcionamento. Os conteúdos são aqueles que encontram pouco ou nenhum espaço na grande mídia. Em geral, abordam assuntos que afetam diretamente a vida das populações em seu local de moradia e na vida cotidiana, a partir da mobilização social.

Surgem também, a partir de 1996, no Brasil, os canais comunitários na tevê a cabo, que estão construindo uma outra modalidade de comunicação local. No principal modelo deste tipo de canal, a grade de programação, por exemplo, é ocupada por entidades associadas que partilham o espaço eqüitativamente, o que resulta numa programação diferente daquela da televisão comercial, pois não está presa a padrões, nem possui uma unidade de linguagem entre os programas. Estes, em geral, 
carecem de qualidade técnica, mas os canais representam uma oportunidade para novos atores ocuparem o espectro televisivo como emissores de conteúdos.

Em estudo sobre a TV Fênix, de Campinas (SP), Marcio A. Rivera (2004, p. 95) demonstra que a lógica dos canais comunitários se baliza por parâmetros diversos dos da televisão comercial:

O canal comunitário é um espaço aberto para que as organizações civis sem fins lucrativos partilhem a expressão televisiva. Esta partilha, fundada em ações de gestão e organização, pode contribuir ao fortalecimento das pessoas e entidades civis interessadas em promover o desenvolvimento local sob uma lógica progressista e de bem público ${ }^{10}$.

Por sua vez, a televisão comunitária na Colômbia, que se inicia já nos anos 1980, também incorpora a perspectiva de gestão pelas próprias comunidades. Atualmente ela está regulamentada como "serviço de televisão prestado pelas comunidades organizadas sem fins lucrativos, com o objetivo de realizar e produzir sua própria programação para satisfazer necessidades educativas, recreativas e culturais" (Téllez Garzón, 2004, p. 4) ${ }^{11}$.

Portanto, quando se fala de comunicação comunitária, está implícito o sentido de um processo que envolve a participação popular autônoma, da gestão à produção de conteúdos, ou seja, trata-se de uma comunicação destinada a atender demandas locais mediante o exercício da cidadania a partir dos próprios cidadãos. Suas diferenças em relação à mídia local comercial são claras, embora possa atuar no mesmo universo territorial e temático.

\section{Tendências do jornalismo regional/local}

Pressupõe-se que o jornalismo local seja aquele que retrate a realidade regional ou local, trabalhando, portanto, a informação de proximidade. O meio de comunicação local tem a pos-

10. Cf. também, na presente edição de Comunicação \& Sociedade, o artigo "Pantallas comunitarias: conquistar una televisión dada", que Marcio Rivera co-assina com Sérgio Ferreira do Amaral.

11. Cf. igualmente, na presente edição de Comunicação \& Sociedade, o artigo de Téllez Garzón, "La televisión comunitaria en Colombia: entre la realidad y la utopía”. 
sibilidade de mostrar melhor do que qualquer outro a vida em determinadas regiões, municípios, cidades, vilas, bairros, zonas rurais etc. Por vezes, se cerca de distorções, como as que têm origem em vínculos com interesses político-partidários e econômicos, mas, mesmo acarretando vieses de informação, acaba contribuindo na divulgação de temas locais. Está num contexto vantajoso para o leitor ou telespectador, ou seja, a proximidade da informação. As pessoas acompanham os acontecimentos de forma mais direta, pela vivência ou presença pessoal, o que possibilita o confronto entre os fatos e sua versão midiática de forma mais natural.

$\mathrm{Na}$ prática, o jornalismo local vem revelando algumas tendências. Os laços políticos locais tendem a ser fortes e a comprometer a informação de qualidade. É comum a existência de tratamento tendencioso da informação e até a omissão de fatos, em decorrência de ligações políticas com os detentores do poder local e dos interesses econômicos de donos da mídia. Claro que não se trata apenas de um problema da imprensa regional, mas nela parece que essas relações se tornam mais explicitas, justamente porque as possibilidades de confronto entre o fato e sua versão, por parte do leitor, são mais fáceis de acontecer.

Um instrumento bastante usado, nesse sentido, em cidades do interior, são os press-releases emitidos pelas assessorias de comunicação dos poderes executivo e legislativo, principalmente, mas também das instituições privadas. Vângela de Morais (2003, p. 83), analisando a cobertura de um incêndio florestal pelos jornais Brasil Norte e Folha de Boa Vista, de Roraima, constata a existência de um tratamento superficial dado ao acontecimento em todas as etapas do processo de produção da notícia, a começar pela pauta.

Atrelada aos interesses administrativos, a pauta nasce com a feição oficial, gerada a partir da iniciativa governamental, estendida, quando muito, a instituições e grupos organizados da sociedade civil. (...) O que se observa são posturas incorporadas ao cotidiano jornalístico que 
contribuem para um certo enviesamento tendencioso da notícia, além de refletir a ausência de contexto, investigação e profundidade. O episódio do grande incêndio, por várias vezes, se traduziu em expressões valorativas e de personificação. Os estreitos vínculos entre o jornal e a política partidária deram a voz, exprimiram a imagem, sugeriram a ação.

Vângela (2003, p. 74) vê as assessorias de comunicação locais como agentes diretos da notícia, mediante releases ou informações mediadas pelos assessores, além de um "jornalismo declaratório", preso, por excelência às fontes oficiais ${ }^{12}$.

Essa prática também foi detectada por Letícia Pinto da Costa. Em pesquisa sobre o jornal $A$ Voz do Vale do Paraíba, da cidade de Taubaté (SP), a autora (2002, p. 78) comprovou que "a maior parte dos textos, bem como das fotografias, ambos sobre temas locais, é fornecida pelas assessorias de imprensa de instituições públicas e privadas"13. Continua ela, referindo-se ao mesmo jornal: "Em todos os tipos de assuntos, é comum também encontrar em suas páginas a reprodução de notícias veiculadas por outros jornais", o que denota o aproveitamento integral de releases pela mídia impressa local. Complementa (2002, p. 72) relatando que um dos assessores entrevistados afirmou que o jornal $A$ Voz do Vale do Paraíba "publica praticamente tudo" o que a assessoria de imprensa da prefeitura de Taubaté divulga. E, mais adiante, faz uma avaliação:

Nesse jornal, os assessores de imprensa são peça fundamental no produto noticioso que chega até o leitor. Ao apresentar um material "pronto e acabado", [o pessoal do jornal só tinha o trabalho de digitar os textos, já que na época os releases ainda eram enviados por fax]. Tendo em vista a infra-estrutura precária da empresa em questão, no que diz respeito à mão-de-obra jornalística, os assessores ajudam a determinar o que será noticiado ao público. São eles que desempenham a função do jornalista da redação - já que seus textos são reproduzidos na integra pelo jornal. Ao "sugerir" como tal matéria deve ser colocada na edição

12. Cf. também, na presente edição de Comunicação \& Sociedade, o artigo de Vângela, "A mídia impressa local: uma agenda de constrangimentos e motivações".

13. "As demais são obtidas por meio de agências de notícias, da internet e de assessorias de imprensa de outras localidades" (Costa, 2002, p. 78). 
do dia seguinte, mais do que "repórteres", eles passam a ter também a função de editor do jornal. Sem eles, dificilmente o jornal de Waldemar Duarte sairia às bancas e com notícias sobre a cidade. Trata-se, portanto, da "fórmula ideal": economiza-se tempo e dinheiro (Costa, 2002, p. 86).

A autora (2002, p. 91) afirma que “as edições analisadas mostram com clareza a parcialidade do jornal em relação aos políticos que ocuparam, nos períodos estudados, cargos eletivos (prefeitos e vereadores), bem como às pessoas - no caso, secretários municipais - ligadas a esses governantes". Outra nuance esclarecedora de seu estudo é que ele evidencia que a ligação do jornal com os políticos da região não é, propriamente, de cunho partidário, mas de envolvimento com quem está no exercício do poder. Eventos na área da educação, por exemplo, tais como inaugurações (construção ou ampliação de escolas pela prefeitura) e a presumível "boa" aplicação do dinheiro público (investimentos), ganharam amplos espaços no jornal no período analisado ${ }^{14}$.

No caso dos jornais de Roraima, a análise da narrativa dos incêndios permitiu a Vângela de Morais (2003, p. 107) concluir que

a editoração opinativa atravessando manchetes, títulos, leads, enfim, a totalidade da mensagem e do apelo informativo [fez] ruir velhos preceitos de imparcialidade; [que houve] a personificação excessiva do governador Naudo Campos, ora com referências positivas (jornal Brasil Norte), ora com a ênfase negativista (jornal Folha de Boa Vista); [que] a abordagem dos incêndios [se deu] pela ótica das disputas e intrigas políticas locais, [fazendo sucumbir] a ótica ambientalista.

Assim, a concessão de primazia às fontes oficiais, a importância dada ao "jornalismo declaratório", o aproveitamento intencional e acrítico de releases e a ligação política e política-partidária vêm comprometendo a qualidade da informação em jornais de capitais e cidades do interior.

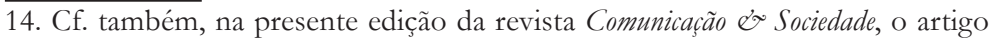
de Letícia, "O newsmaking na imprensa do interior: a rotina produtiva do jornal $A$ Voz do Vale do Paraíba".

80 - Comunicação e Sociedade 43 
Outra tendência é a falta de ampla cobertura e de apuração de acontecimentos, tanto no nível local como no regional. Ela se deve a uma estrutura de produção pequena, com poucos profissionais e, às vezes, até despreparados para o exercício do jornalismo. Acrescente-se, em alguns casos, a opção administrativa de donos de veículos locais, de aceitar com naturalidade o exercício de um jornalismo baseado em fontes oficiais, já que isso garante a sobrevivência do veículo. Nessas condições o jornalismo local deixa de explorar seu imenso potencial de trabalhar com a informação isenta e atender a todos os setores que perfilam a vida de uma "comunidade". Perde, assim, uma oportunidade de mercado, a de trabalhar com competência a informação de proximidade, que é a razão de ser da imprensa local.

Entendemos por informação de proximidade aquela que expressa as especifidades de uma dada localidade, que retrate, portanto, os acontecimentos orgânicos a uma determinada região e seja capaz de ouvir e externar os diferentes pontos de vista, principalmente a partir dos cidadãos, das organizações e dos diferentes segmentos sociais. Enfim, a mídia de proximidade caracteriza-se por vínculos de pertença, enraizados na vivência e refletidos num compromisso com o lugar e com a informação de qualidade e não apenas com as forças políticas e econômicas no exercício do poder.

Também é muito comum existir a tendência de a mídia local reproduzir a grande-imprensa, ao imitar o estilo de tratamento da informação ou dedicar amplos espaços para notícias nacionais e internacionais, às vezes por exigência das matrizes, como no caso das redes de televisão, ou então como estratégia operativa. Por meio de contrato com agências de notícias, reprodução de colunas de articulistas renomados ou mesmo a apropriação de temas tratados em reportagens especiais, muitos jornais locais tendem a se ocupar mais de assuntos comumente tratados pelos jornais de circulação nacional do que com assuntos específicos locais que demandariam apuração jornalística e, possivelmente, a exposição pública do meio informativo diante de fatos, que, por vezes, a imprensa local não aborda para não prejudicar seus próprios interesses. 
Parece que há, no país, um tipo de jornalismo que se torna quase como um padrão, passando a ser reproduzido por jornais das capitais dos estados e de cidades do interior. Referimo-nos aos assuntos típicos das editoriais de política, economia, cidades, polícia etc., que são amplamente tratados pelos jornais de circulação nacional, como também por aqueles de cidades do interior. Ou seja, a imprensa do interior tende a cobrir os mesmos tipos de assuntos, como pleitos eleitorais, atos dos poderes públicos, desfalques, assaltos, assassinatos, acidentes, intempéries etc. A diferença é que sua ocorrência é regional ou local.

No entanto, há que se levar em conta que também os jornais de circulação nacional não deixam de ter seu lado local. Se, por um lado, eles focam temas como política, economia e segurança, nacional e internacional, por outro, falam igualmente de suas cidades-sede, da política local, dos problemas urbanos locais e assim por diante. É o caso de veículos como Folha de S.Paulo e Jornal do Brasil, que ocupam grande parte de suas páginas com assuntos das capitais onde se localizam suas sedes administrativas e editoriais ${ }^{15}$.

No que se refere aos jornais de bairro, tomando por base vários dos que se editam no município de São Paulo (Jabaquara News, São Paulo Zona Sul, Jornal da Liberdade, Gazeta Penhense, Ipiranga News, Gazeta do Ipiranga, Gazeta do Tatuapé etc.), a tendência é a produção de veículos de baixo interesse jornalístico, com matérias frias, cumplicidade editorial evidente com ocupantes (ou aspirantes) de cargos públicos no poder legislativo e com forças econômicas locais que lhes dão sustentação e a destinação do espaço, majoritariamente, para anúncios publicitários. Pelo que denota, este tipo de jornal de bairro tem como razão de ser, sobretudo, a captação de recursos provindos da publicidade e de outras formas de financiamento de suas operações, mais do que prover o bairro com notícias de interesse local. Esvazia-se a função jornalística. Esquece-se que ao leitor interessa não só matéria paga, mas também informação de qualidade e vinculada a seu mundo diário, em que é capaz de identificar atores, con-

15. O mesmo fenômeno já foi observado por João Mesquita (apud Camponez, 2002, p.107), referindo-se à imprensa nacional com sede em Lisboa e no Porto. 
frontar abordagens com os fatos reais e intercambiar impressões no nível da comunicação interpessoal.

Há ainda outras vertentes de mídia local que se diferenciam totalmente das configurações analisadas até aqui. São os canais de uso gratuito na tevê a cabo - canais universitários, legislativos, educativo-culturais, comunitários e o do judiciário - e as rádios, os jornais e as tevês comunitárias de rua. São meios regidos por estruturas organizativas e estratégias de programação diferentes. Estão sob a égide do legislativo, do judiciário, de universidades, de associações comunitárias etc. Não buscam a grande audiência, mas segmentos bem definidos. O espaço da programação - no caso dos canais universitários e comunitários - é dividido eqüitativamente entre entidades associadas. Embora haja distorções (mau uso de alguns destes canais), os propósitos globais da programação não deixam de ser legal e eticamente educativo-culturais, de desenvolvimento comunitário e em prol da cidadania.

\section{Consideração final}

À guisa de conclusão, poder-se-ia dizer que a mídia de proximidade se constitui numa demanda regional e local. Há interesse das pessoas em ver os temas de suas localidades retratados na mídia, como também há interesse por parte da mídia em ocupar o espaço regional com vistas a atingir seus objetivos mercadológicos.

Mas, os jornais e as televisões, na prática, estão envolvidos em contradições, motivadas por vínculos políticos e interesses econômicos, que, além de comprometer a informação de qualidade e isenta, acabam por reproduzir estilos e menosprezar a força do local enquanto fonte de informação.

\section{Referências}

BOURDIN, Alain. A questão local. Rio de Janeiro: DP\&A, 2001.

CAMPONEZ, Carlos. Jornalismo de proximidade. Coimbra: Minerva, 2002.

COSTA, Letícia M.Pinto da. Vozes dissonantes na imprensa do interior: a produção e a recepção do jornal "A Voz do Vale do Paraíba". São Bernardo do Campo: PósCom-Umesp, 2002. (Dissertação - Mestrado em Comunicação Social). 
CRUZ, Dulce Márcia. Televisão e negócio: a RBS em Santa Catarina. Florianópolis: UFSC, 1996.

LOPEZ GARCIA, Xosé. Médios locais do futuro e com futuro. In: LEDO ANDIÓN, Margarita e KUNSCH, Margarida M. Krohling (orgs.). Comunicación audiovisual: investigación e formación universitárias. II Colóquio Brasil-Estado Espanhol de Ciências da Comunicación. Santiago de Compostela: Universidad de Santiago de Compostela/ Intercom, 1999.

HALL, Stuart. A identidade cultural na pós-modernidade. Rio de Janeiro: DP\&Z, 1998.

MATTOS, Sergio. A televisão no Brasil: 50 anos de história (1950-2000). Salvador: Pas/Ianamá, 2000.

MORAIS, Vângela Maria Isidoro de. O incêndio florestal na imprensa roraimense: uma análise a partir dos jornais "Folha de Boa Vista" e "Brasil Norte". São Paulo: ECA-USP, 2003. (Dissertação - Mestrado em Ciências da Comunicação).

ORTIZ, Renato. Um outro território. In: BOLAÑO, César R. S. (org.). Globalização e regionalização das comunicações. São Paulo: Educ/Editora da UFS/ Intercom, 1999. p. 51-72.

PERUZZO, Cicília M. Krohling. Mídia local e suas interfaces com a mídia comunitária. Anuário Unesco-Umesp de Comunicação Regional. São Bernardo do Campo: Cátedra Unesco-Umesp, 2003. p. 52-78.

REIMÃo, Sandra. Televisão na América Latina. São Bernardo do Campo: Editora Umesp, 2000.

SANTOS, Milton. A naturez̧a do espaço. São Paulo: Edusp, 2002.

SILVA, Carla Pollake da. O adolescente e a televisão regional: estudo da audiência do programa "Em Movimento". São Bernardo do Campo: PósCom-Umesp, 2003. (Dissertação - Mestrado em Comunicação Social).

TÉLLEZ GARZÓN, María Patricia. La televisión comunitaria en Colombia: entre la realidad y la utopía. VII CONGRESO LATINOAMERICANO DE INVESTIGADORES DE LA COMUNICACIÓN, VII, 2004, La Plata (Argentina). Alaic/Universidad Nacional de la Plata, 11-16 out. 2004. [Paper apresentado no GT de Medios Comunitarios y Ciudadanía]. 